\title{
Saudi myocardial infarction patients' learning needs: Implications for cardiac education program
}

\author{
Salman H. Alsaqri (Associate Professor) ${ }^{\mathrm{a}}$, Mohannad J. Alkuwaisi (MSN) ${ }^{\mathrm{b}, *}$, \\ Zainab M. Shafie (Assistance Professor) ${ }^{\mathrm{b}}$, Mohammed K. Aldalaykeh (Assistance Professor) ${ }^{\mathrm{c}}$, \\ Mohammad Alboliteeh (Associate Professor) ${ }^{\mathrm{d}}$ \\ ${ }^{a}$ Medical Surgical Department, College of Nursing, University of Hail, Hail, Saudi Arabia \\ ${ }^{\mathrm{b}}$ Nursing Department, UNISZA, Terengganu, Malaysia \\ ${ }^{\mathrm{c} C o m m u n i t y ~ a n d ~ M e n t a l ~ H e a l t h ~ N u r s i n g ~ D e p a r t m e n t, ~ C o l l e g e ~ o f ~ N u r s i n g, ~ U n i v e r s i t y ~ o f ~ S c i e n c e ~ a n d ~ T e c h n o l o g y, ~ J o r d a n ~}$ \\ ${ }^{\mathrm{d}}$ Nursing Leadership and Management, College of Nursing, University of Hail, Hail, Saudi Arabia
}

\section{A R T I C L E I N F O}

\section{Keywords:}

Saudi patients

MI

Learning needs

Demographic characteristics

\begin{abstract}
A B S T R A C T
Background: Providing information for myocardial infarction patients is an important nursing function and is part of the role of health-care professionals delivering cardiac education. It is essential to acknowledge and incorporate the self-perceived needs of patients into the information they receive. Hospital stays are becoming shorter, reducing the opportunities for nurses to provide pre-discharge information to patients. This highlights the challenge of adequately assessing and meeting patients' Learning needs.

Aims and objectives: To explore the Learning needs of patients who have received treatment for a myocardial infarction before their hospital discharge. Also, to examine differences in learning needs among patients according to their demographic characteristics.

Materials and methods: A descriptive, cross-sectional, design was used to answer the research questions. A convenient sample of 55 patients interviewed in a coronary care unit at large north-western hospital in Saudi Arabia. Cardiac Patients Learning Needs Inventory (CPLNI) was used to collect data.

Results: Information about risk factors, anatomy and physiology, and medication were the most valued information by MI patients prior to discharge. There was a statistically significant difference between patients' total learning needs according to their socio-demographic characteristics. Younger patients needed more information than older ones. Highly educated patients needed more information than those in the uneducated group.

Conclusion: This study suggests that MI patients have high learning needs within 24-48 h before hospital discharge. In addition, patients' learning needs vary according to their demographic characteristics.

Relevance to clinical practice: Assessment of MI patients' information needs before their discharge from hospital helps in developing effective cardiac educational programme that will help these patients in their recovery at home.
\end{abstract}

\section{Introduction}

Acute myocardial infarction (MI) is a main cause of the rapid increase in the number of admission cases and death toll not only in Saudi Arabia but worldwide. ${ }^{1}$ Each year, about 130974 Saudis suffer from MI, and the number of people living with the effects of coronary heart disease (CHD) is growing. ${ }^{1}$ The raised number of MI led to a financial impact on both the hospital and the patients, the direct medical costs for coronary heart disease (CHD) are expected to triple from US $\$ 272.5$ billion in 2010 to US $\$ 818.1$ billion in $2030 .^{2}$ Growing healthcare costs have induced hospitals to attempt to decrease the length of hospital stay. ${ }^{3}$ Decreasing hospital length stays compromises the effectiveness and efficacy of the education because of reducing a time for teaching patients necessary information, and the information becomes condensed. ${ }^{3}$ Therefore, it is important to determine patients' learning needs to make effective use of time based on these needs.

The 'needs-based' method has been supported as a way of teaching cardiac patients during hospitalization. ${ }^{4}$ Instead of telling standard

\footnotetext{
* Corresponding author. Nursing Department, UNISZA, Terengganu, Malaysia.

E-mail addresses: s.alsaqri@uoh.edu.sa (S.H. Alsaqri), Mj.alkwiese@uoh.edu.sa (M.J. Alkuwaisi), zainab69@unisza.edu.my (Z.M. Shafie), mkaldalaykeh@just.edu.jo (M.K. Aldalaykeh),dr.alboliteeh@gmail.com (M. Alboliteeh).
} 
information and implementing educational programmes designed for all patients with little regard of patients' learning needs, this method tries to find out and fulfill the patient learning needs. Learning needs are defined as the topical areas of interest perceived by the individual as important to learn. ${ }^{4}$ The inclusion of learning needs into the design of the patient education teaching session is a key element in the process of teaching and learning, as they reflect the patient's personal health experience and improve their ability to cuddle self-care behaviors. ${ }^{5}$ Educational programs should be prepared to enhance the physical and psychological well-being, the quality of life, and reduce the complications and dangers of death. ${ }^{6}$ However, these goals may not be reached without patients receiving suitable information and education on how they can manage their own symptoms. ${ }^{7}$ Therefore, it is obligatory for the nurses to comprehend the patients' physical, psychosocial and spiritual learning needs before an effective education process takes place.

Moreover, patients' needs and nurses' expectations of these needs are often inconsistent. ${ }^{7}$ Nurses concentrate on information related to the disease process, other than significant information regarding adaptation and lifestyle modification. ${ }^{8}$ This sort of inconsistency may lead to poor education, ${ }^{9}$ and patients express dissatisfaction toward the information delivered and that patients' learning needs will not be achieved. ${ }^{9}$ Therefore, patient-centered care is recommended, and for this end programs based on patients' learning needs are established. ${ }^{6}$ Otherwise, patients who are not furnished with the suitable information that rooted from their learning needs may be risky to a number of problems such as the rise in the readmission rates. ${ }^{6}$

In South-Western Saudi Arabia, there is not any well-arranged education programme for patients with MI before their hospital discharge, and it is hard for these patients to get assistance if they require it. Moreover, there is no willingness of any community health services to provide help and follow up after discharge. In addition, there is a lack of published studies in the Middle East regarding learning needs of patients with MI. To the best of our knowledge, this is the first study that will investigate learning needs of Saudi patients with MI before hospital discharges in order to help healthcare providers establish an educational programme that will aid these patients in their recovery at home.

\section{Aims and objectives}

\subsection{Research questions}

This study attempt to examine MI patients' perceptions of their learning needs before hospital discharge. Therefore, this study accordingly covers the next research questions: What are the perceived learning needs of Saudi patients admitted with MI before hospital discharge? Which educational items appear the top priorities of learning for patients with MI? Are there any significant differences in the learning needs perceived by patients with MI in terms of age, gender, educational level, and working status?

\section{Methods}

\subsection{Research design \& setting}

A descriptive, cross-sectional, correlational design was used to guide this study. The accessible population were all patients in the coronary care unit (CCU) in one of the largest hospitals at Northwestern Saudi Arabia.

\subsection{Sample}

Patients were requested to participate through a convenience sampling technique between July 2019 and September 2019. Participants were included in the study if they: ${ }^{1}$ were 20 years or older. ${ }^{2}$ had MI for the first time ${ }^{3}$ finished the instrument before discharge from the hospital; ${ }^{4}$ were able to communicate verbally in Arabic language; ${ }^{5}$ and were fully conscious. Patients were excluded from this study if they ${ }^{1}$ suffer from serious co-morbidity or psychiatric illness; ${ }^{2}$ used narcotic analgesic for pain. A total of 55 patients were included in this study.

\subsection{Data collection}

Interviews were accomplished by qualified research assistants. Patients who decided to participate were given general information about the study and its objectives through this interview. After signing the informed consent form, patients were requested to fill out the sociodemographic sheet. As well cardiac patients learning needs inventory (CPLNI) were also collected in this interview.

\subsection{Research instrument}

The patient's sociodemographic sheet contained questions to disclose information about age, gender, work status, and educational level, which were examined to find their relationship to the patients' learning needs. Data regarding MI patients' learning needs were collected through the cardiac patients learning needs inventory (CPLNI). This scale was originally established by Gerard ${ }^{10}$ and revised for use in the UK by Turton. ${ }^{11}$ The original questionnaire contained 43 items clustered by subject matter into eight groups ('introduction to the CCU', 'anatomy and physiology', 'psychological factors', 'risk factors', 'medication information', 'diet information', 'physical activity' and 'other pertinent information'). 'Introduction to the CCU' was not applied by Turton. ${ }^{11}$ The questionnaire applied in this study was Turton's form ${ }^{11}$ and it included 37 items clustered into seven groups ('anatomy and physiology', 'psychological factors', 'risk factors', 'medication information', 'diet information', 'physical activity' and 'other pertinent information'. Each item starts with the stem 'I need to know'. The respondents were requested to score the items into one of five importance levels, from 'not important' (NI), to 'very important' (VI). In the analysis, these levels were scored from 1 to 5 . Following Turton, a 'not applicable' section was also involved. Turton also retitled the group term risk factor, lifestyle factor, as patients seemed to misunderstand the former. Total scores range from 40 to 200, and the mean score can be obtained for each subscale individually or for the total scale. Higher scores indicates high needs of information. ${ }^{12}$ The CPLNI had earlier undergone both reliability and validity testing ${ }^{11}$ and was piloted by Turton. In this study, face validity and content validity were established for the Arabic version of the CPLNI, and it showed excellent Internal consistency reliability (Cronbach's alpha $=0.91$ ). The CPLNI was translated into Arabic according to the techniques proposed by Cha, Kim. ${ }^{13}$ Before embarking on the full study, a pilot study was undertaken to evaluate the feasibility of the design, readability of the items and reliability of the questionnaire. ${ }^{12}$ The final Arabic CPLNI questionnaire was distributed to five MI patients before discharge from the hospital. Data were collected from the patients using a structured interview. The researcher provided a verbal explanation of the study purposes, read each question to them and wrote the answer according to patients responses. The pilot study results indicated that the CPLNI was in general easy to understand and readable. The interview for each patient took $15-20 \mathrm{~min}$ to complete.

\subsection{Ethical considerations}

The ethical principles were checked out and approved by the Saudi Ethical Committee for Scientific Research. Before the beginning of data collection, the study's purposes, benefits, and risks were discussed with the participants, and they were guaranteed that participation in the study was voluntary. Additionally, it was made understandable to all participants that the data would be offered in a group format, and anonymity and confidentiality were guaranteed. After agreeing to 
participate in the study, each participant signed a written informed consent form.

\subsection{Data analysis}

The Statistical Package for Social Sciences (SPSS) software package for Windows, version 25, was used for data analysis. Descriptive and inferential statistics were used to answer research questions. Statistically significant level for all tests was set at (a) alpha $<0.05$. Descriptive statistics were used to describe the study sample, and their demographic as well as patients' perception of learning needs. Independent $t$-test was used to examine the difference between perceived learning needs according to patients' gender and work condition before their discharge from the hospital. One-way analysis of variance (ANOVA) followed by Scheffe's post hoc test was used to examine differences in the learning needs according to age and level of education. Pearson correlation coefficient was used to examine relationships between patients' learning need and their age in years.

\section{Results}

\subsection{Demographic characteristics of the patients}

The 55 patients who completed the CPLNI consisted primarily of middle-aged patients (mean $=52.25$ years, SD 16.87) with the range of $20-85$ years and were mainly men (80\%). Most of the participants were married $(76,4 \%)$, the majority of them were school education $(40 \%)$, and more than half of them were working (56.4\%) (Table 1).

\subsection{Description of the learning needs of MI patients}

All participants highly rated the needs of all types of information. Table 2 shows that the mean of the learning needs as perceived by the patients was 3.81 ( $\mathrm{SD}=0.54)$. The categories ranked by patients as most important were risk factors (mean $=4.10, \mathrm{SD}=0.64$ ), followed by anatomy and physiology (mean $=3.98, \mathrm{SD}=0.69$ ), and medication information (mean $=3.82$, SD.84).

\subsection{Relationship between demographic variables and learning needs}

The results showed a significant negative relationship between total learning needs and age $(\mathrm{r}=-0.37, \mathrm{p}=0.05)$. The results revealed a statistically significant difference between total learning needs and patients' age groups $(\mathrm{F}=3.52, \mathrm{p}=0.037)$ in which younger patients needed more information than older patients did $(\mathrm{p}=0.03)$. Moreover, there was statistically significant difference between total learning needs and level of education $(F=4.38, p=0.017)$ in which highly educated $(\mathrm{p}=0.018)$ patients needed more information than the

Table 1

Socio-demographic characteristics of the patients $(n=55)$.

\begin{tabular}{lll}
\hline Variable & Frequency & $\%$ \\
\hline Gender & 44 & 80 \\
$\quad$ Male & 11 & 20 \\
$\quad$ Female & & \\
Age & 10 & 18.2 \\
$\quad$ Younger & 28 & 50.9 \\
$\quad$ Middle age & 17 & 30.9 \\
$\quad$ Older & 16 & \\
Level of Education & 22 & 29.1 \\
$\quad$ Non Educated & 17 & 40 \\
$\quad$ School & & 30.9 \\
$\quad$ University Education & 31 & \\
Working & 24 & 56.4 \\
$\quad$ Yes & & 43.6 \\
No & &
\end{tabular}

Table 2

Description of learning needs of MI patients $(n=55)$.

\begin{tabular}{llll}
\hline Priority & Category & Mean $^{\mathrm{a}}$ & SD \\
\hline 1 & Risk factors & 4.10 & .64 \\
2 & Anatomy and physiology & 3.98 & .69 \\
3 & Medication information & 3.82 & .84 \\
4 & Psychological factors & 3.77 & .68 \\
5 & Other pertinent information & 3.74 & .82 \\
6 & Diet information & 3.69 & .78 \\
7 & Physical activity & 3.57 & .79 \\
& Total & 3.81 & .54 \\
\hline
\end{tabular}

a Possible range $=1-5$.

Table 3

Difference Between Groups for Selected Demographics and total learning needs $(n=55)$.

\begin{tabular}{llllllll}
\hline Variables & $\mathrm{n}$ & $\mathrm{Mean}$ & $\mathrm{SD}$ & $\mathrm{F}$ & $\mathrm{df1}$ & $\mathrm{df2}$ & $\mathrm{p}$ \\
\hline Age & 10 & 4.14 & .34 & 3.52 & 2 & 52 & .03 \\
$\quad$ Younger & 28 & 3.82 & .53 & & & & \\
$\quad$ Middle age & 17 & 3.59 & .58 & & & & \\
$\quad$ Old & & & & & & & \\
$\quad$ Level of Education & 16 & 3.56 & .78 & 4.38 & 2 & 52 & .017 \\
$\quad$ Non Educated & 22 & 3.78 & .37 & & & & \\
$\quad 17$ & 4.09 & .30 & & & & \\
$\quad$ School & & & & & & & \\
$\quad$ Wniversity Education & & & & $\mathrm{t}$ & $\mathrm{df}$ & & \\
$\quad$ Yerking & 31 & 3.89 & .40 & -1.17 & 53 & & .24 \\
$\quad$ No & 24 & 3.71 & .67 & & & & \\
\hline
\end{tabular}

uneducated group (Table 3).

Not statistically significant differences were also observed in learning needs based on the working condition of patients $(\mathrm{t}=-1.17$, $\mathrm{p}=0.24$ ) in which patients who worked required the same information as those who did not work. Moreover, not statistically significant differences between men and women in their perceptions of the total learning needs $(\mathrm{p}=0.61)$ in which men reported the same learning needs as women (Table 3$)$.

\section{Discussion}

This is the first study to report about post-MI patient learning needs in Saudi Arabia. The results of this study showed that Saudi MI patients had high need for information before their discharge from the hospital. They rated their information needs as important and very important. In fact, this tendency (patients' learning needs being directed toward higher responses) might indicate urgent needs among patients at this critical time, and this might be because they felt they had a second chance in life. Therefore, the survivors wish to know everything about leading their new life with new, emerging challenges.

The rating of the different subscales suggests which general topic areas covered by the CPLNI were most important for the patients. The three most popular subscales valued by MI patients prior to discharge were: information about risk factors, anatomy and physiology, and medication information. Previous studies have also reported that postMI patients tend to have high learning need about medication information. $^{14-16}$ Patients consider information about medication important because they may understand that the treatment of myocardial infarction takes a long time and therefore feel it is important to understand as much as possible about their medication.

Similarly, other studies have also showed that post-MI patients report high information needs related to anatomy and physiology to be a high-level information need. ${ }^{14,17}$ There are also some studies which have found only moderate-level learning needs related to anatomy and physiology. ${ }^{16,18}$ These findings are not surprising because many times in order for the patient to understand the MI disease process, they need 
to understand the basic structure of the heart, how it works, and what happens to heart muscles during an MI incidence. These information needs would be most relevant to patients in the predischarge period to manage their care at home. These findings support the view that postMI patients perceive practical information relevant to survival as being of prime importance. ${ }^{16,19}$ However, the fact that all categories are viewed as important to very important is arguably more important than their precise rank order.

The results of this study indicated that there was a significant relationship between age groups and the total scores of the learning needs. Younger patients reported more information needs than older patients. This is consistent with the previous studies. ${ }^{14,15}$ However, this is inconsistent with a previous study that was carried out in the UK. ${ }^{20}$ which reported that older patients need more information than younger patients. This could be attributed to the cultural environment wherein elderly people from eastern communities live in a familial context; therefore, they feel dependent on their families during the recovery period. In contrast, elderly people in western communities live independently. Because such patients are expected to be responsible for their own recovery, they recognize their increased responsibility after MI. Therefore, they request more information than younger patients do. In addition, older patients may have more opportunity to contact with individuals who have had heart disease. ${ }^{21}$ Other possible explanation is older patients might regard a cardiac event as a consequence of the aging process and might think that their role of leading an active life has almost ended. On the contrary, younger patients still expect to attain many goals in life; therefore, they might be more motivated to search for information that will help them return to this active role. Moreover, the result of this study is also inconsistent with other studies that did not demonstrate any relationship between patients' age and their learning needs. ${ }^{18,22}$

The results of this study indicated that there was a significant difference in the total scores of learning needs according to the level of education. Highly educated patients reported more learning needs than uneducated patients. This result is inconsistent with the results of previous studies. ${ }^{18,23}$ One possible explanation is that patients who are uneducated are not normally interested in learning about things that are considered to be unfamiliar to them. ${ }^{14}$ This confirms that there were no significant differences between groups in the items with which the educated were familiar such as medications, anatomy and physiology and risk factors because they feel that they can understand these items.

Comparison of the overall CPLNI scores by gender revealed that there were not significant differences in the perceived overall importance of learning needs of information. Men reported the same information needs as women. This supports the results of Hamdan FR, and Hussein SZ studies ${ }^{18,24}$ who found no statistically significant differences between gender and learning needs, but is inconsistent with the results of other studies ${ }^{23,25}$ that found that statistically significant differences between gender and learning needs. This can be explained by the women and men in this study were working and were educated. In Saudi community, women study and work as men, so they rated learning needs the same as men did. Furthermore, women in Saudi culture may have the same authority to call the doctor or to be interested about the tests that must be carried out after discharge, so they were the same interested in ranking information needs as an important factor compared with men.

Whilst the literature offers very little discussion about working and learning needs, result of the current study indicated that there was not a significant relationship between the total scores of the learning needs and working status of the patients. Patients who were working ranked the same learning needs as patients who were not working. This result is consistent with the result by Hussein SZ, Nor HatyBinti Hassan ${ }^{24}$ who found that post MI, patients who work needed the same information as patients who do not work but is inconsistent with the result by Smith and Liles ${ }^{20}$ who stated that retired people desired more information than employed people. One possible explanation is that Saudi patients who are working or not working may experience the same stress in their recovery, so the same need to understand how to cope with issues that may arise after discharge.

\section{Conclusion}

Post-MI, Saudi patients have several needs with high priority, particularly more information about risk factor, anatomy and physiology, and medications. There were statistically significant differences in the total learning needs according to patient's demographic characteristics. Younger and middle-aged patients need more information than older ones in the areas of diet information' and the total learning needs. Highly educated and school-level groups need more information than uneducated group in the areas of 'medication information', 'other pertinent information 'and the total learning needs. Men need the same information as women in all the categories of CPLNI. Working patients need the same information as non-working patients in all the categories of CPLNI except in 'physical activity', working patients need more information than non-work patients.

\section{Implications for nursing practice}

The results of this study suggest that MI patients need more information within $24-48 \mathrm{~h}$ before their discharge from hospital. Specific information about risk factor, anatomy and physiology, and medications should be considered for MI patients before discharge from the hospital. Therefore, Saudi healthcare providers should structure the content of patient's education programme around these items that scored high. Findings of this study indicate that there is variability in patient information needs that validate the need for individual assessment of learning needs by healthcare providers. Specific educational programmes should be developed for older and uneducated patients depending on their level of understanding.

\section{Limitations of the study}

Generalization of the findings of this study is limited because of the use of convenience sampling from one hospital, which leads to selection bias. However, the hospital is the only hospital who have cardiac center in Saudi Arabia. Another limitation is related to the nature of crosssectional design which prevents us from establishing causality relationship between study variables. Future studies should use random sampling methods with multi-sites for data collection, and use longitudinal studies with multiple points of data collection.

\section{Declaration of competing interest}

The authors declare that they have no conflict of interests.

\section{Acknowledgements}

The authors would like to thank those who helped them in king Khalid Hospital, Hail, Saudi Arabia. The research investigators would like to express their gratitude toward the University of Hail for funding this project and we are indebted to all the patients who freely gave their time to participate in this study.

\section{References}

1. Aldoori NM. Prevalence of obesity among female adolescents in al-hillah city: future risk of cardiovascular diseases. Res J Pharm Technol. 2017;10(7):2127-2131.

2. Asaria P, Elliott P, Douglass M. Acute myocardial infarction hospital admissions and deaths in England: a national follow-back and follow-forward record-linkage study (vol 4, pg e191, 2017). Lancet Publ Health. 2017;2(4):E165-E.

3. Yu M-M, Chair SY, Chan CW, Choi KC. Information needs of older people with heart failure: listening to their own voice. J Geriatr Cardiol: JGC. 2016;13(5):435.

4. Redman BK. The Practice of Patient Education: A Case Study Approach. Elsevier Health 
Sciences; 2007

5. Schulman-Green D, Jaser S, Martin F, et al. Processes of self-management in chronic illness. J Nurs Scholarsh. 2012;44(2):136-144.

6. Tingström PR, Kamwendo K, Bergdahl B. Effects of a problem-based learning rehabilitation programme on quality of life in patients with coronary artery disease. Eur $J$ Cardiovasc Nurs. 2005;4(4):324-330.

7. Evanoff B, Potter P, Wolf L, Grayson D, Dunagan C, Boxerman S. Can We Talk? Priorities for Patient Care Differed Among Health Care Providers. 2005; 2005.

8. Suhonen R, Nenonen H, Laukka A, Välimäki M. Patients' informational needs and information received do not correspond in hospital. J Clin Nurs. 2005;14(10):1167-1176.

9. Bethell HJ, Evans JA, Turner SC, Lewin RJ. The rise and fall of cardiac rehabilitation in the United Kingdom since 1998. J Publ Health. 2006;29(1):57-61.

10. Gerard P, Peterson L. Learning needs of cardiac patients. Cardio-vascular Nurs. 1984;20(2):7.

11. Turton J. Importance of information following myocardial infarction: a study of the self-perceived information needs of patients and their spouse/partner compared with the perceptions of nursing staff. J Adv Nurs. 1998;27(4):770-778

12. Alkubati SA, Al-Zaru IM, Khater W, Ammouri AA. Perceived learning needs of Yemeni patients after coronary artery bypass graft surgery. J Clin Nurs. 2013;22(7 8):930-938.

13. Cha ES, Kim KH, Erlen JA. Translation of scales in cross-cultural research: issues and techniques. J Adv Nurs. 2007;58(4):386-395.

14. Almamari RS, Lazarus ER, Muliira JK. Information needs of post myocardial infarction patients in Oman. Clin Epidemiol Glob Health. 2019;7(4):629-633.

15. Eshah NF. Jordanian acute coronary syndrome patients' learning needs: Implications for cardiac rehabilitation and secondary prevention programs. Nurs Health Sci. 2011;13(3):238-245.

16. Huriani E. Myocardial infarction patients' learning needs: perceptions of patients, family members and nurses. Int J Nurs Sci. 2019;6:294-299.

17. Egan F. Current approaches to cardiac in-patient education. Nurs Rev Dublin. 1999;17:8-12.

18. Hamdan FRA. Jordanian nurses and acute myocardial infarction patients' perceptions about learning needs. Glob J Med Phys Health Educ. 2015;3:85-99.

19. Yu M, Ying Chair S, Wh Chan C, Li X, Choi KC. Perceived learning needs of patients with heart failure in China: a cross-sectional questionnaire survey. Contemp Nurse. 2012;41(1):70-77.

20. Smith J, Liles C. Information needs before hospital discharge of myocardial infarction patients: a comparative, descriptive study. J Clin Nurs. 2007;16(4):662-671.

21. Fredericks S, Yau T. Clinical effectiveness of individual patient education in heart surgery patients: a systematic review and meta-analysis. Int J Nurs Stud. 2017;65:44-53.

22. Clark JC, Lan VM. Heart failure patient learning needs after hospital discharge. Appl Nurs Res. 2004;17(3):150-157.

23. Greco A, Cappelletti ER, Monzani D, et al. A longitudinal study on the information needs and preferences of patients after an acute coronary syndrome. BMC Fam Pract. 2016;17(1):136

24. Hussein SZ, Nor HatyBinti Hassan. Chan Swee Sin. Hwa Ng Chui, Siew SimSze, Maskon OB. Patients' discharge information needs regarding acute coronary syndrome in teaching hospital. Open Access J Nurs. 2018;1(1):49-58.

25. Polikandrioti M, Babatsikou F. Information to coronary disease patients. Health Sci $J$ 2013;7(1) 